\title{
Demand for Child Immunization of Mothers /Care Givers in Ethiopia: Commentary
}

\author{
Kaleab Tesfaye Tegegne ${ }^{1 *}$, Abiyu Ayalew Assefa ${ }^{1}$, Eleni Tesfaye Tegegne $^{2}$ and Mekibib Kassa \\ Tessema $^{3}$ \\ ${ }^{1}$ Department of Public Health, Hawassa College of health science, Ethiopia \\ ${ }^{2}$ School of Nursing College of Medicine and Health Science, University of Gondar, Ethiopia \\ ${ }^{3}$ Leishmania Research and Treatment Center, University of Gondar, Ethiopia
}

*Corresponding author: Kaleab Tesfaye Tegegne, Department of Public Health, Hawassa College of health science, Hawassa, Ethiopia

\begin{tabular}{|c|c|}
\hline ARTICLE INFO & ABSTRACT \\
\hline Received: 蔧 April 07, 2020 & Citation: Kaleab Tesfaye Tegegne, Abiyu Ayalew Assefa, Eleni Tesfaye Tegegne, Mekibib \\
\hline Published: 幽 April 14, 2021 & Commentary. Biomed J Sci \& Tech Res 35(1)-2021. BJSTR. MS.ID.005647. \\
\hline
\end{tabular}

\section{Introduction}

Universal immunization of children for vaccine-preventable diseases is important in decreasing infant and child death [1]. According to WHO guideline children are received all vaccines when they have got vaccines of BCG, 3 doses of pentavalent vaccine, polio vaccine and measles vaccine [2]. The Ethiopian Federal Ministry of Health has planned before to increase immunization coverage to $80 \%$ of population in $90 \%$ of districts [3].

\section{Data on Vaccination Coverage in Ethiopia}

From children $12-23$ months age, 43\% have got all vaccines, $19 \%$ have not got any vaccine [1] $73 \%$ of children got BCG, $76 \%$ got the first dose of pentavalent, 78\% got the first dose of polio, 74\% got the first dose of PCV, and 73\% got the first dose of rotavirus vaccine. $59 \%$ of children got measles vaccination [1]. Coverage for fully vaccinated or subsequent vaccines was associated with wealth status, education status of care givers or mothers and residence [1]

The Ethiopian mini demographic and health survey of 2019 [1] showed that coverage for fully immunized as well as subsequent vaccines is low relative to the Ethiopian Federal Ministry of Health plan [3]. This indicates identifying contributing factors to increase coverage of immunization at national level in Ethiopia and for this studying determinants of demand for child immunization of mothers/caregivers at national level is important in the future because the mini demographic and health survey conducted in
2019 at national level in Ethiopia failed to include all contributing factors to increase coverage of immunization so we suggest studying determinants of demand for child immunization of mothers/ care givers at national level in Ethiopia is important to increase coverage from the existed level.

Demand for child immunization is mothers or care givers willingness and ability to vaccinate her child [4]. Determinant of demand for child immunization of mothers / care givers in the Ethiopian context may be Grover C. Wirick identified five factors that can have influence on demand for child immunization services of mothers/ care givers. These five factors are
a. Need, desire for prevention
b. A realization of the need.
c. Financial resources

d. A specific motivation to obtain the needed immunization service

e. Availability of immunization service.

We recommend further research to identify determinants of demand for child immunization of mothers /care giver in context of Ethiopia at national level using models of demand for health service by Grover C. Wirick. 


\section{References}

1. (2019) Mini Demographic and Health Survey Ethiopian Public Health Institute Addis Ababa and Federal Ministry of Health Addis Ababa, ICF, Rockville, Maryland, USA.

2. (2017) World Health Organization (WHO) Global Nutrition Monitoring Framework: Operational Guidance for Tracking Progress in Meeting Targets for 2025. Geneva.

\section{ISSN: 2574-1241}

DOI: $10.26717 /$ BJSTR.2021.35.005647

Kaleab Tesfaye Tegegne. Biomed J Sci \& Tech Res

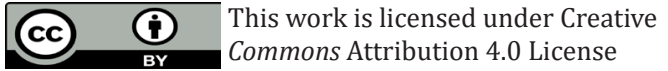

Submission Link: https://biomedres.us/submit-manuscript.php
3. (2015) Immunization Blended Learning Module for the Health Extension Programme, Federal Democratic Republic of Ethiopia Ministry of Health.

4. Andargie G (2008) Introduction to health economics University of Gondar in collaboration with the Ethiopia Public Health Training Initiative, the Carter Center, the Ethiopia Ministry of Health, and the Ethiopia Ministry of Education.

$\begin{array}{ll}\text { BIOMEDICAL } & \text { Assets of Publishing with us } \\ \text { RESEARCHES } & \text { - Global archiving of articles } \\ \text { - Immediate, unrestricted online access }\end{array}$

